\title{
ANALISIS KETIMPANGAN WILAYAH DAN ARAHAN PENGEMBANGAN WILAYAH DI KABUPATEN BURU PROVINSI MALUKU
}

\author{
Analysis Of Regional Imbalance and The Guidance Of Regional \\ Development In Buru Regency Of Maluku Province
}

Rifyan Ruman ${ }^{1}$, Setia Hadi1 ${ }^{1}$, Baba Barus ${ }^{1}$

\begin{abstract}
Abstrak: Tujuan dari penelitian ini adalah untuk mengetahui komoditas unggulan dan kelas kemampuan lahan dan Potensi lahan yang dapat dimanfaatkan untuk pengembangan pertanian di Kabupaten Buru. Metode analisis data yang digunakan adalah Overlay peta, Location Quotient (LQ) dan Shift Share Analysis (SSA) untuk mengetahui komoditas unggulan. Ketimpangan yang terjadi di Kabupaten Buru terlihat dari sarana prasarana yang kurang memadai daam hal ini adalah kondisi jalan yang menjadi akses dari kegiatan masyarakat baik berupa kegiatan ekonomi maupun social dan juga sarana pendidikan dan kesehatan. Berdasarkan analisis LQ dan SSA di Wilayah Kabupaten Buru, Komoditas yang menjadi unggulan di wilayah ini adalah ubi jalar, kacang tanah, kacang hijau, cabai, bawang merah, tomat, bayam, kangkung, labu siam, terong, kacang panjang, bucis, alpokat, mangga, nagka, durian, jeruk, pepaya, rambutan, pisang, jambu mete dan cengkih. Luas potensi lahan yang dapat dimanfaatkan untuk budidaya pertanian untuk tiap kecamatan yaitu Kecamatan Namlea (22390,73 ha), Kecamatan Waeapo (68615,62 ha), Kecamatan Waplau (22173,26 ha), Kecamatan Batabual (7920,27 ha) dan Kecamatan Air Buaya (10985,77 ha) yang dapat dimanfaatkan untuk pembangunan berbasis pertanian sesuai visi dari Kabupaten Buru dan sesuai dengan komoditas unggulan yang ada pada tiap kecamatan. Arahan program pembangunan yang dihasilkan sesuai dengan kondisi yang terjadi berdasarakan hasil dari analisis-analisis sebelumnya yang di rangkum sehingga menghasilkan beberapa arahan program pembangunan untuk tiap kecamatan yang ada di Kabupaten Buru.
\end{abstract}

Kata Kunci : ketimpangan, komoditas unggulan, kemampuan lahan, potensi lahan

\begin{abstract}
The purpose of this study was to determine the class leading commodity and land capability and potential of land that can be used for agricultural development in Buru. Data analysis method used were overlay maps, Location Quotient (LQ) and Shift Share Analysis (SSA) to determine the main commodity. The result is elaborated as follow inequality in Buru can be seen from inadequate infrastructure especially condition of road, education and health facilities. Based on analysis of LQ and SSA in the Buru Regency, Commodities priorities in this region are sweet potatoes, peanuts, green beans, peppers, onion, tomato, spinach, kale, squash, eggplant, beans, avocado, mango, jack fruit, durian, orange, papaya, banana, cashew and clove. The potential cultivate land for each sub-districts as Namlea (22390.73 ha), District Waeapo (68615.62 ha), District of Waplau (22173.26 ha), District Batabual (7920.27 ha) and District Air Buaya (10985.77 ha) that can be utilized for the development of agriculture-based according to the vision of Buru and in accordance with the commodity that exist in each district. Referrals
\end{abstract}

\footnotetext{
${ }^{1}$ Program Studi Ilmu Perencanaan Wilayah, Sekolah Pascasarjana Institut Pertanian Bogor
} 
development program produced in accordance with the conditions result that had been summarized thus producing some direction for each sub-district development program in the Buru Regency.

Keywords : disparities, leading commodities, land capability, land potential

\section{PENDAHULUAN}

Ketimpangan pembangunan terjadi dalam skala lokal dan nasional (Mopangga, 2011). Masalah kesenjangan regional di tingkat pembangunan sosial dan ekonomi adalah fenomena universal. Fenomena ini merupakan hasil alami dari proses pembangunan itu sendiri, dimana daerah-daerah tertentu berkembang lebih cepat daripada yang lain karena sejumlah faktor seperti sumberdaya alam dan fisik, perbedaan parameter sosial dan sikap, struktur kelembagaan dan kebijakan diskriminatif dari negara (Mohiuddin dan Hashia, 2012). Analisis fisik dan lingkungan telah banyak digunakan untuk mengenali karakteristik sumber daya alam di suatu wilayah atau kawasan. Analisis tersebut dapat dilakukan dengan menelaah kemampuan dan kesesuaian lahan. Tujuannya, agar penggunaan lahan dalam pengembangan wilayah dan/atau kawasan dapat berjalan secara optimal dengan tetap memperhatikan keseimbangan ekosistem (Nashiha et al., 2015). Syafruddin et al., (2004) mengemukakan bahwa untuk membangun sektor pertanian yang kuat, berproduksi tinggi, efisien, berdaya saing tinggi, dan berkelanjutan perlu dilakukan penataan sistem pertanian dan penetapan komoditas unggulan di setiap wilayah pengembangan disertai kebijakan pemerintah daerah yang tepat.

Kabupaten Buru memiliki potensi sumberdaya alam dan lahan yang tinggi serta merupakan wilayah penyangga pertumbuhan ekonomi Kota Ambon. Sumberdaya lahan merupakan salah satu pertimbangan dalam melaksanakan pembangunan suatu wilayah. Pertimbangan tersebut bertujuan agar sumberdaya lahan dapat menghasilkan manfaat yang sebesar-besarnya sepanjang kehidupan manusia. Untuk itu maka diperlukan pemanfaatan lahan secara lestari dan berkelanjutan sehingga dapat meningkatkan produktivitas lahan itu sendiri sehingga bermanfaat juga untuk sektor penelitian atau sektor yang lain (Mahalaya, 1989).

Pemerintah Kabupaten Buru dengan visinya masyarakat sejahtera dan demokratis yang berbasis pertanian, bermaksud mengembangkan perekonomian regionalnya berbasis sumberdaya alam dan agribisnis. Rencana kebijakan ini dalam implementasinya akan melibatkan seluruh komponen masyarakat dalam suatu kelompok usaha tani, dimana masyarakat disiapkan untuk merespon rencana dari setiap program pembangunan pertanian melalui pendekatan wilayah dengan menetapkan kawasan - kawasan pengembangan dalam suatu permukiman yang lebih produktif guna meminimalisir kesenjangan antara kota dan desa. Oleh karena itu pengembangan pertanian sesuai komoditas unggulan wilayah yang sesuai dengan kemampuan dan potensi lahan yang tersedia di Kabupaten Buru menjadi penting sehingga hal ini juga dapat mengurangi kesenjangan yang terjadi.

Penelitian ini bertujuan untuk 1) melihat ketimpangan pembangunan yang terjadi di Kabupaten Buru, 2)menentukan komoditas unggulan wilayah di Kabupaten Buru, 3)mengetahui kemampuan dan potensi lahan untuk pengembangan pertanian, 4)menghasilkan arahan program pembangunan di Kabupaten Buru.

\section{METODE PENELITIAN}

Penelitian dilakukan di wilayah Kabupaten Buru yang terdiri dari 5 kecamatan yaitu Namlea, Waeapo, Waplau, Batabual dan Air Buaya, lokasi penelitian dapat dilihat pada Gambar 1. Waktu penelitian Maret - Agustus 2015. 
Data yang digunakan dalam penelitian ini adalah data primer dan sekunder. Data primer diperoleh dari survei lapangan melalui wawancara dan pengamatan lapangan. Data sekunder adalah data curah hujan, peta topografi, peta administrasi kabupaten, peta lereng dan elevasi, peta RTRW kabupaten, peta penggunaan lahan, peta tanah yang bersumber dari hasil inventarisasi dan penelusuran data baik pada buku, peta, internet, perundangundangan, penelitian terdahulu, maupun dari beberapa instansi terkait, baik instansi pemerintah di daerah maupun pusat, atau instansi/lembaga independen lainnya.

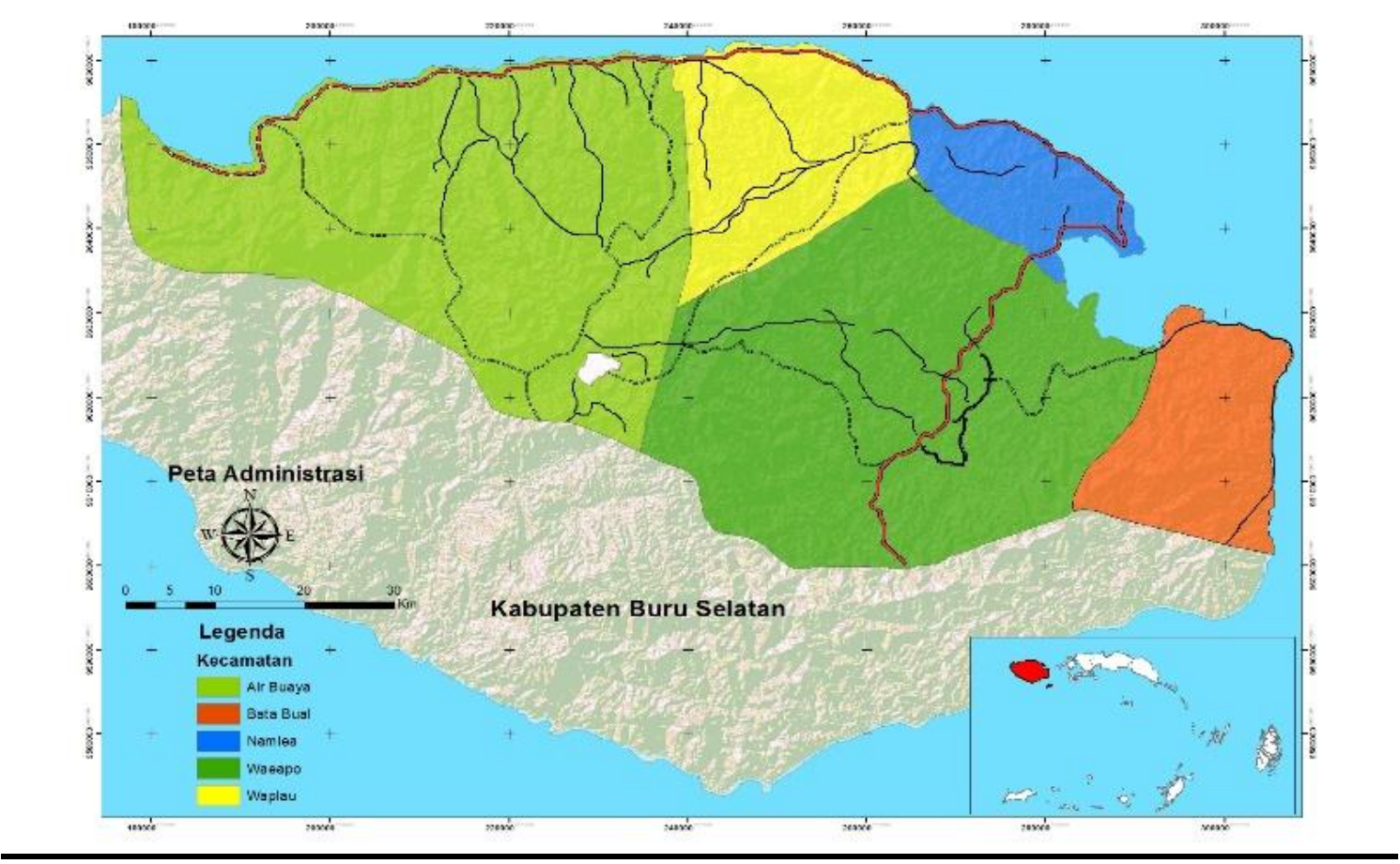

Gambar 1 Peta Lokasi Penelitian

Data yang digunakan dalam penelitian ini adalah data primer dan sekunder. Data primer diperoleh dari survei lapangan melalui wawancara dan pengamatan lapangan. Data sekunder adalah data curah hujan, peta topografi, peta administrasi kabupaten, peta lereng dan elevasi, peta RTRW kabupaten, peta penggunaan lahan, peta tanah yang bersumber dari hasil inventarisasi dan penelusuran data baik pada buku, peta, internet, perundangundangan, penelitian terdahulu, maupun dari beberapa instansi terkait, baik instansi pemerintah di daerah maupun pusat, atau instansi/lembaga independen lainnya.

\section{Metode Analisis Data}

\section{Ketimpangan Pembangunan Antar Wilayah}

Metode yang dipakai untuk melihat disparitas pembangunan antar wilayah adalah analisis skalogram danidentifikasi sarana prasarana seperti kondisi jalan, sarana pendidikan dan sarana kesehatan, serta menghitung indeks rasionya.

\section{Penentuan Komoditas Unggulan}

Sektor unggulan merupakan sektor perekonomian yang diharapkan menjadi motor penggerak perekonomian wilayah. Dengan mengetahui dan mengoptimalkan sektor unggulan ini maka diharapkan terdapat efek positif bagi kemajuan aktivitas perekonomian 
daerah (Syahidin, 2006). Metode yang sering dipakai sebagai indikasi sektor basis adalah metode Location Quotient (LQ) dan Shift Share Analysis (SSA) (Rustiadi et.al, 2011). Penentuan komoditas unggulan dilihat berdasarkan nilai LQ dan SSA, dimana jika nilai LQ $>1$ dan nilai SSAnya bernilai positif maka dikatakan kecamatan tersebut memiliki komoditas unggulan atau terjadi pemusatan aktifitas.

Analisi LQ merupakan analisis yang digunakan untuk menunjukkan lokasi pemusatan/basis (aktifitas) dalam hal ini pemusatan komoditas.

$$
L Q i j=\frac{X i j / X i}{X . j / X}
$$

Dimana $\quad \mathrm{LQ}_{\mathrm{ij}} \quad=$ Nilai Aktivitas ke $\mathrm{j}$ pada unit wilayah $\mathrm{j}$

$\mathrm{X}_{\mathrm{i}} \quad=$ jumlah seluruh aktivitas di unit wilayah ke-i

$\mathrm{X}_{\mathrm{j}} \quad=$ Jumlah aktivitas ke $\mathrm{j}$ di seluruh unit wilayah

X... = Besaran aktivitas total diseluruh unit wilayah

Shift Share Analysis (SSA) merupakan salah satu dari sekian banyak teknik analisis untuk memahami pergeseran struktur aktivitas di suatu lokasi tertentu dibandingkan dengan suatu referensi (dengan cakupan wilayah lebih luas) dalam dua titik waktu. Persamaan analisis SSA adalah sebagai berikut:

$$
S S A=\left(\frac{X . .(t 1)}{X . .(t o)}-1\right)+\left(\frac{X i(t 1)}{X i(t 0)}-\frac{X . .(t 1)}{X . .(t 0)}\right)+\left(\frac{X i j(t 1)}{X i j(t 0)}-\frac{X i(t 1)}{X i(t 0)}\right)
$$

Dimana:

a $\quad=$ komponen share,

$\mathrm{b} \quad=$ komponen proportional shift,

c $\quad=$ komponen differential shift

$\mathrm{X}_{\mathrm{i}} \quad=$ Nilai total komoditas tertentu di unit wilayah ke-i

$\mathrm{X}_{\mathrm{ij}} \quad=$ Nilai di wilayah ke-i dan aktivitas ke-j

$\mathrm{t}_{1} \quad=$ titik tahun akhir $\mathrm{t}_{0}=$ titik tahun awal

\section{Analisis Kemampuan dan Potensi Lahan}

Analisis kemampuan lahan dihasilkan dari evaluasi peta landsystem dan peta lereng sehingga menghasilkan peta kemampuan lahan Kabupaten Buru. Sistem klasifikasi kemampuan lahan mengacu pada sistem yang digunakan Amerika Serikat (United States Departement of Agriculture). Pengelompokan kelas kemampuan lahan dalam sistem tersebut dilakukan secara kualitatif dan merupakan pendekatan pertama dari pendekatan dua tahap (FAO, 1976). Sistem ini mengenal tiga kategori, yaitu kelas, sub-kelas dan unit. Penggolongan kedalam kelas, sub-kelas dan unit didasarkan atas kemampuan lahan tersebut memproduksi komoditas pertanian secara umum tanpa menimbulkan kerusakan dalam jangka panjang. Dalam sistem ini sifat kimia tanah tidak digunakan sebagai pembeda karena sifat kimia tanah sangat mudah berubah, sehingga kurang relevan untuk digunakan. Sifatsifat tanah/lahan yang digunakan sebagai pembeda hanyalah sifat-sifat fisik/morfologi tanah yang dapat dapat diamati di lapangan (Hardjowigeno dan Widiatmaka, 2007).

Analisis Potensi lahan menggunakan peta kemampuan lahan yang di overlay dengan peta penggunaan lahan yang dapat dimanfaatkan (semak belukar, semak belukar rawa, lahan terbuka) untuk pengembangan pertanian di Kabupaten Buru. Hasil output ini kemudian digunakan sebagai pertimbangan arahan program pembangunan di Kabupaten Buru.

Evaluasi Kemampuan lahan pada dasarnya merupakan evaluasi potensi sumberdaya lahan untuk penggunaan berbagai sistem pertanian secara luas yang tidak membicarakan 
peruntukan jenis tanaman tertentu ataupun tindakan-tindakan pengelolaannya. Klasifikasi kemampuan lahan yang dianalisis adalah klasifikasi kemampuan lahan dalam tingkat kelas dan sub kelas. Terdapat beberapa parameter yang digunakan dalam analisis yaitu kemiringan lereng, drainase tanah, tingkat erosi dan kepekaan erosi, tekstur tanah serta kedalaman tanah.

\section{Arahan Program Pembangunan}

Arahan program pembangunan dalam mengatasi masalah disparitas di Kabupaten Buru dilakukan dengan menggunakan hasil sintesis dari ketiga analisis sebelumnya dan presepsi masyarakat.

\section{HASIL DAN PEMBAHASAN}

\section{Ketimpangan Pembangunan Antar Wilayah}

Hasil perhitungan rasio akses jalan per kecamatan maka dihasilkan status akses di Kabupaten Buru, Kecamatan Namlea dan Kecamatan Batabual memiliki status pelayanan yang buruk yang bermakna jumlah penduduk yang terlayani lebih sedikit, sedangkan tiga kecamatan lainnya memiliki rasio pelayanan yang baik (Tabel 1). Secara keruangan dua kecamatan tersebut terletak di wilayah pantai timur (Gambar 2).

Seperti yang telah dijelaskan sebelumnya bahwa infrastruktur jalan sangat mendukung kegiatan sosial dan ekonomi masyarakat. Kecamatan Namlea sebagai ibu kota kabupaten memiliki status akses jalan yang buruk, jika dibandingkan dengan Kecamatan Waeapo yang memiliki status akses jalan baik hal ini dikarenakan Kecamatan Waeapo merupakan daerah transmigran dan juga sebagai lumbung padi untuk Kabupaten Buru serta Provinsi Maluku.

Tabel 1 Panjang Jalan (km) Menurut Kondisi Jalan dan Kecamatan di Kabupaten Buru

\begin{tabular}{llllllll}
\hline Kecamatan & $\begin{array}{l}\text { Jumlah } \\
\text { Penduduk }\end{array}$ & Baik & $\begin{array}{l}\text { Rusak } \\
\text { Ringan }\end{array}$ & $\begin{array}{l}\text { Rusak } \\
\text { Berat }\end{array}$ & $\begin{array}{l}\text { Jumlah } \\
\text { Total }\end{array}$ & $\begin{array}{l}\text { Rasio } \\
\text { Pelayanan } \\
(2 / 6)\end{array}$ & Status \\
\hline$(1)$ & $(2)$ & $(3)$ & $(4)$ & $(5)$ & $(6)$ & $(7)$ & $(8)$ \\
\hline Namlea & 38.201 & 78,62 & 38,1 & 41,95 & 158,67 & 240,76 & Buruk \\
Waeapo & 35.112 & 183,33 & 114,4 & 281,85 & 579,58 & 60,58 & Baik \\
Waplau & 10.036 & 27,78 & 11,8 & 65,19 & 104,77 & 95,79 & Baik \\
Batabual & 8.393 & 13,7 & 14,2 & 46,1 & 74 & 113,42 & Buruk \\
Air Buaya & 19.705 & 44,08 & 21,48 & 102,49 & 168,05 & 117,26 & Baik \\
\hline Buru & 111.447 & 347,51 & 199,98 & 537,58 & $1.085,77$ & & \\
\hline
\end{tabular}

Sumber : Kabupaten Buru dalam angka, 2013

Infrastruktur yang dapat mempengaruhi ketimpangan wilayah adalah fasilitas pendidikan. Ketimpangan pendidikan merupakan faktor yang signifikan membentuk tingkat pertumbuhan ekonomi (Pose dan Tselios, 2010). Hasil hirarki pelayanan fasilitas pendidikan dapat dilihat pada Tabel 2. Hasil analisis skalogram untuk fasilitas pendidikan menunjukkan pelayanan yang rendah terjadi pada Kecamatan Namlea, Waeapo dan Air Buaya (Hirarki III), sedangkan kecamatan lainnya lebih baik. Secara keruangan hal tersebut digambarkan pada Gambar 3 yang menunjukkan pola ketimpangan pelayanan fasilitas pendidikan yang lebih menyebar. 


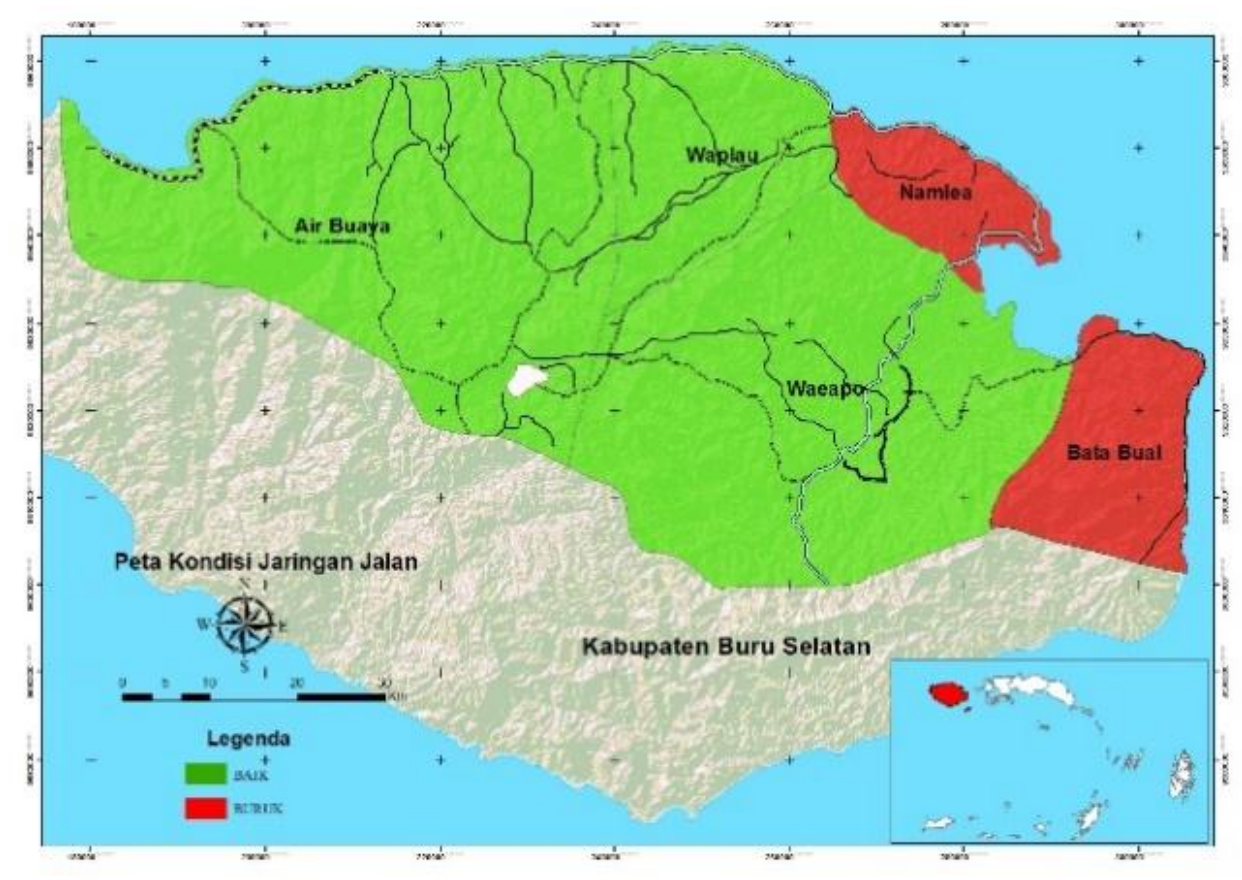

Gambar 2 Peta Jaringan Jalan Kabupaten Buru

Tabel 2 Sebaran Fasilitas Pendidikan dan Hasil Penetapan Hirarki di Kabupaten Buru

\begin{tabular}{|c|c|c|c|c|}
\hline Kecamatan & $\begin{array}{l}\text { Jumlah } \\
\text { Penduduk }\end{array}$ & $\begin{array}{l}\text { Jumlah Indeks } \\
\text { Perkembangan } \\
\text { Wilayah }\end{array}$ & $\begin{array}{lr}\text { Jumlah } & \text { Keberadaan } \\
\text { Fasilitas } & \text { Pendidikan per } \\
\text { Wilayah } & \\
\end{array}$ & Hirarki \\
\hline Namlea & 38201 & 3,11 & 3 & HIRARKI III \\
\hline Waeapo & 35112 & 5,47 & 6 & HIRARKI III \\
\hline Waplau & 10036 & 7,24 & 6 & HIRARKI I \\
\hline Batabual & 8393 & 6,55 & 5 & HIRARKI II \\
\hline \multirow[t]{3}{*}{ Air Buaya } & 19705 & 5,01 & 5 & HIRARKI III \\
\hline & Rataan & 5,48 & & \\
\hline & Stdev & 1,59 & & \\
\hline
\end{tabular}

Sumber : Kabupaten Buru Dalam Angka (diolah), 2013

Tabel 3 Sebaran Fasilitas Kesehatan dan Hasil Penetapan Hirarki di Kabupaten Buru

\begin{tabular}{llllll}
\hline \multirow{2}{*}{ Kecamatan } & $\begin{array}{l}\text { Jumlah } \\
\text { Penduduk }\end{array}$ & $\begin{array}{l}\text { Jumlah Indeks } \\
\text { Perkembangan } \\
\text { Wilayah }\end{array}$ & $\begin{array}{l}\text { Jumlah } \\
\text { Fasilitas } \\
\text { Wilayah }\end{array}$ & $\begin{array}{c}\text { Keberadaan } \\
\text { Kesehatan per }\end{array}$ & Hirarki \\
\hline Namlea & 38201 & 9,46 & 11 & HIRARKI III \\
Waeapo & 35112 & 13,24 & 14 & HIRARKI III \\
Waplau & 10036 & 18,08 & 12 & HIRARKI II \\
Batabual & 8393 & 11,32 & 7 & HIRARKI III \\
Air Buaya & 19705 & 18,54 & 16 & HIRARKI I \\
\hline & Rataan & 14,13 & & \\
\hline
\end{tabular}

Sumber : Kabupaten Buru dalam angka (diolah), 2013

Hasil hirarki pelayanan fasilitas kesehatan dapat dilihat pada Tabel 3. Gambar 4 menunjukan pola ketimpangan pelayanan fasilitas kesehatan yang terjadi pada kecamatan kecamatan yang ada di sebelah timur yaitu Kecamatan Namlea, Waeapo dan Batabual yang 
menunjukkan tingkat pelayanan rendah (hirarki III), sedangkan kecamatan lainnya lebih baik. Penyediaan fasilitas kesehatan merupakan salah satu kebutuhan untuk meningkatkan kondisi kesehatan masyarakat dan upaya pemerintah dalam menyediakan fasilitas kesehatan seperti rumah sakit, puskesmas, dan puskesmas pembantu mengalami peningkatan walaupun dinilai masih belum mencukupi. Jumlah puskesmas yang ada pada tahun 2012 sebesar 10 unit, sedangkan puskesmas pembantu sebanyak 43 unit.

\section{Identifikasi Komoditas Unggulan}

Informasi tentang kecamatan yang memiliki komoditas unggulan penting diketahui karena sekaligus mencerminkan perwilayahan komoditas (Sari MR, 2010). Komoditas unggulan di Kecamatan Namlea sebanyak 14 komoditas yaitu ubi jalar, kacang tanah, kacang hijau, bayam, kangkung, terong, buncis, alpokat, mangga, nangka, pepaya, pisang, dan jambu mete, Kecamatan Weapo dengan 9 komoditas yaitu cabai, tomat, labu siam, terong, buncis, alpokat, nangka, durian dan jeruk, Kecamatan Waplau dengan 7 komoditas yaitu kacang tanah, kacang hijau, cabai, bawang merah, jeruk dan jambu mete, Kecamatan Batabual dengan 6 komoditas yaitu tomat, bayam, kangkung, kacang panjang, jeruk dan cengkih, Kecamatan Air Buaya dengan 6 komoditas yaitu bayam, labu siam, kacang panjang, mangga, duren dan pepaya. Untuk persebaran komoditas unggulan di Kabupaten Buru lebih detail dapat dilihat pada Gambar 5.

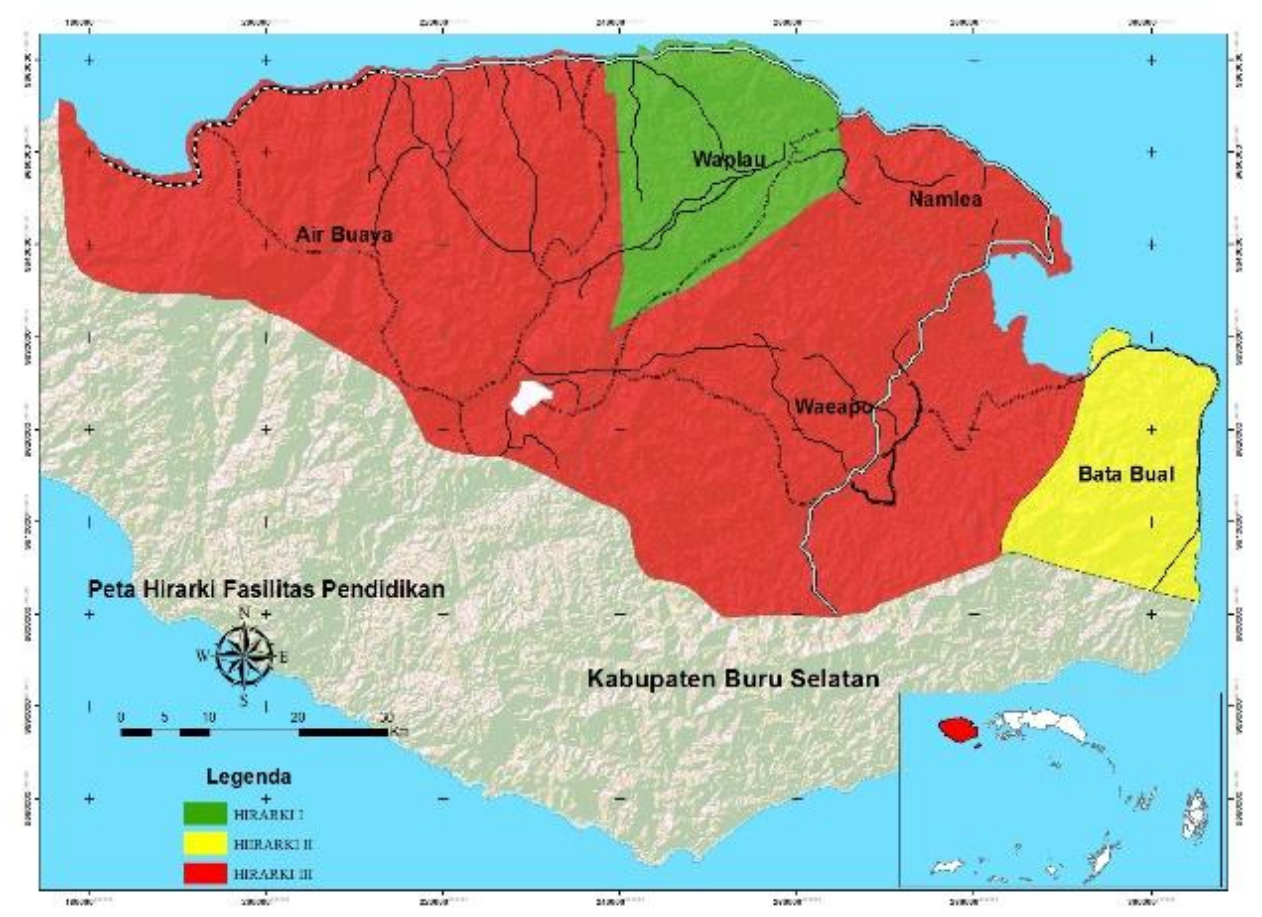

Gambar 3 Peta Hirarki Fasilitas Pendidikan 


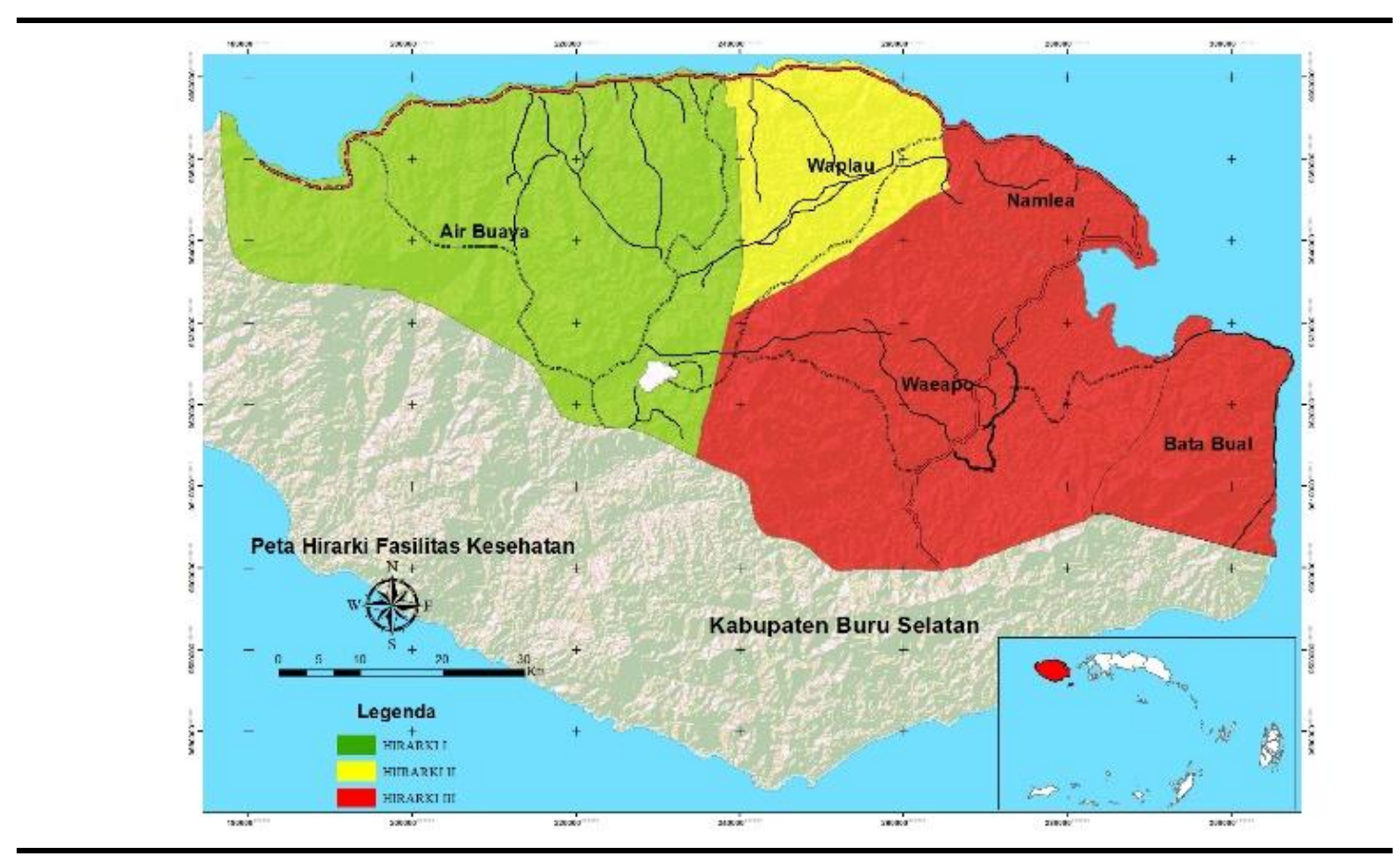

Gambar 4 Peta Hirarki Fasilitas Kesehatan

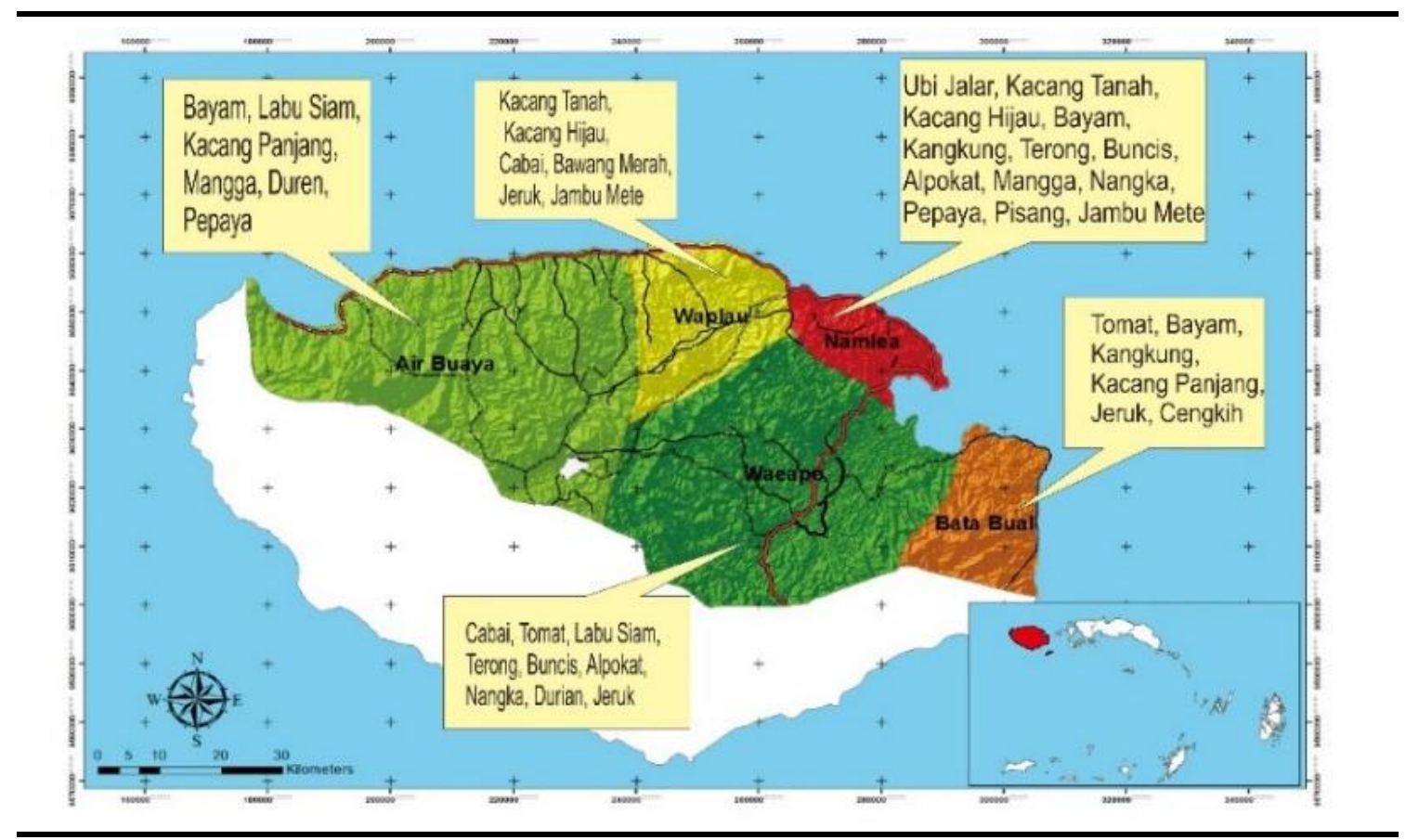

\section{Gambar 5 Peta Sebaran Komoditas Unggulan}

\section{Identifikasi Kelas Kemampuan dan Potensi Lahan}

Kemampuan lahan yang terdapat di Kabupaten Buru dapat dilihat pada Gambar 6 dimana lahan dengan kelas I-IV yang dapat dimanfaatkan untuk pertanian lebih banyak di 
bagian tegah wilayah, sedangkan wilayah barat (Kecamatan Air Buaya) dan wilayah timur (Kecamatan Batabual) lebih didominasi oleh lahan dengan kelas VI-VIII. Setelah mengetahui kemampuan lahan yang ada selanjutnya hasil ini di overlay dengan lahan yang belum dimanfaatkan sehingga diperoleh potensi dari lahan yang tersedia (Gambar 7) dimana lahan yang berpotensi ini menyebar hanya di bagian tengah wilayah.
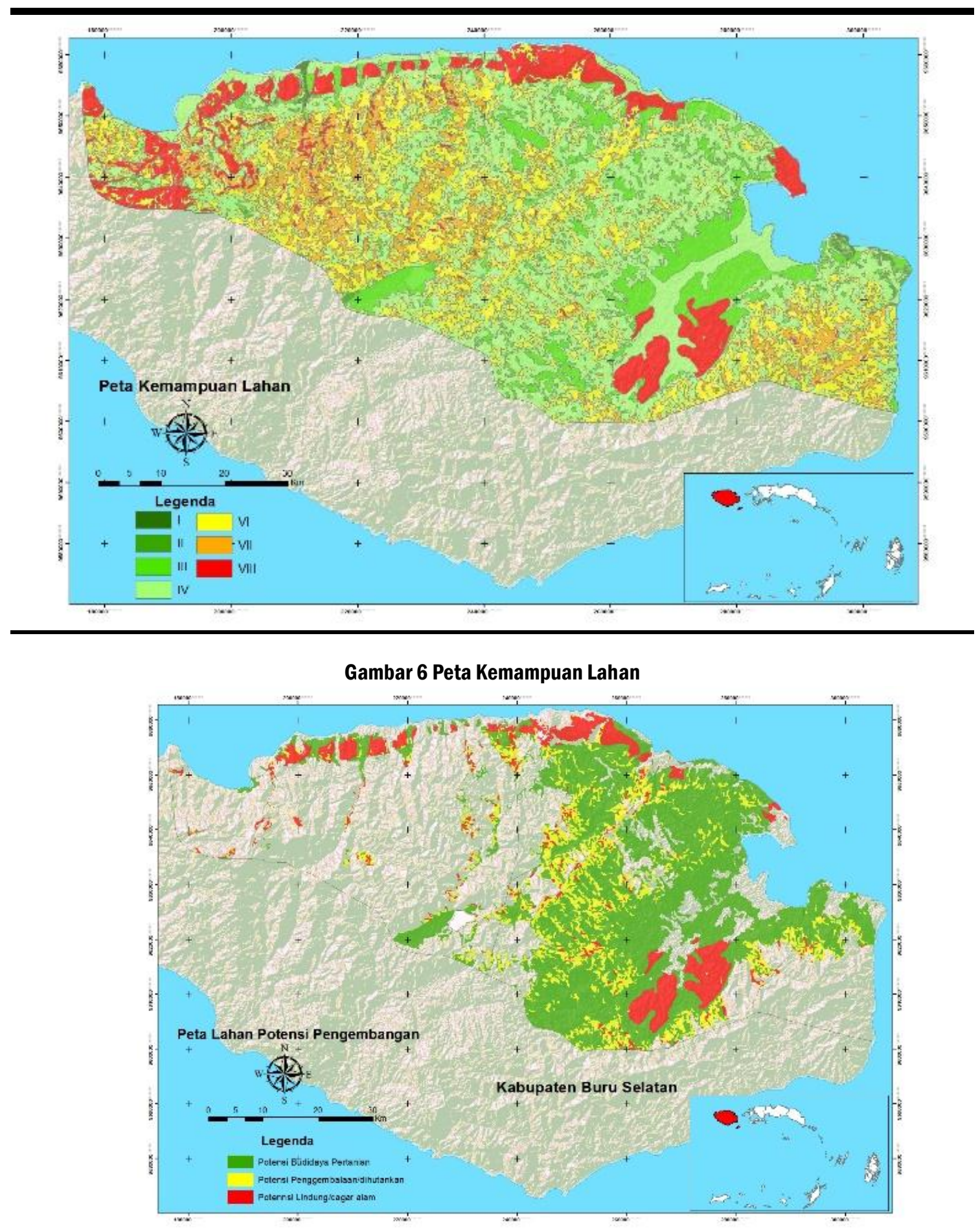

Gambar 7 Peta Potensi Lahan 
Kelas kemampuan lahan IV terdapat di semua kecamatan di Kabupaten Buru dengan Kecamatan Namlea yang memiliki persentase terbanyak dengan total total luas sebesar 71,27 persen, kemudian diikuti berturut - turut Kecamatan Waeapo 65,75 persen dan Waplau 51,07 persen, sedangkan pada Kecamatan Batabual dan Air Buaya kelas kemampuan lahan terluas adalah kelas VI dengan total luasan 50,33 persen dan 39,60 persen. Untuk melihat sebaran total luasan kelas kemampuan lahan di Kabupaten Buru dapat di lihat pada Gambar 8. Total luasan dari lahan yang dapat dimanfaatkan untuk pengembangan budidaya pertanian dapat dilihat pada Gambar 9 yang menunjukkan total luasan lahan yang dapat dimanfaatkan untuk budidaya pertanian pad tiap kecamatan yaitu Kecamatan Namlea (22390,73 ha), Kecamatan Waeapo (68615,62 ha), Kecamatan Waplau (22173,26 ha), Kecamatan Batabual (7920,27 ha) dan Kecamatan Air Buaya (10985,77 ha).

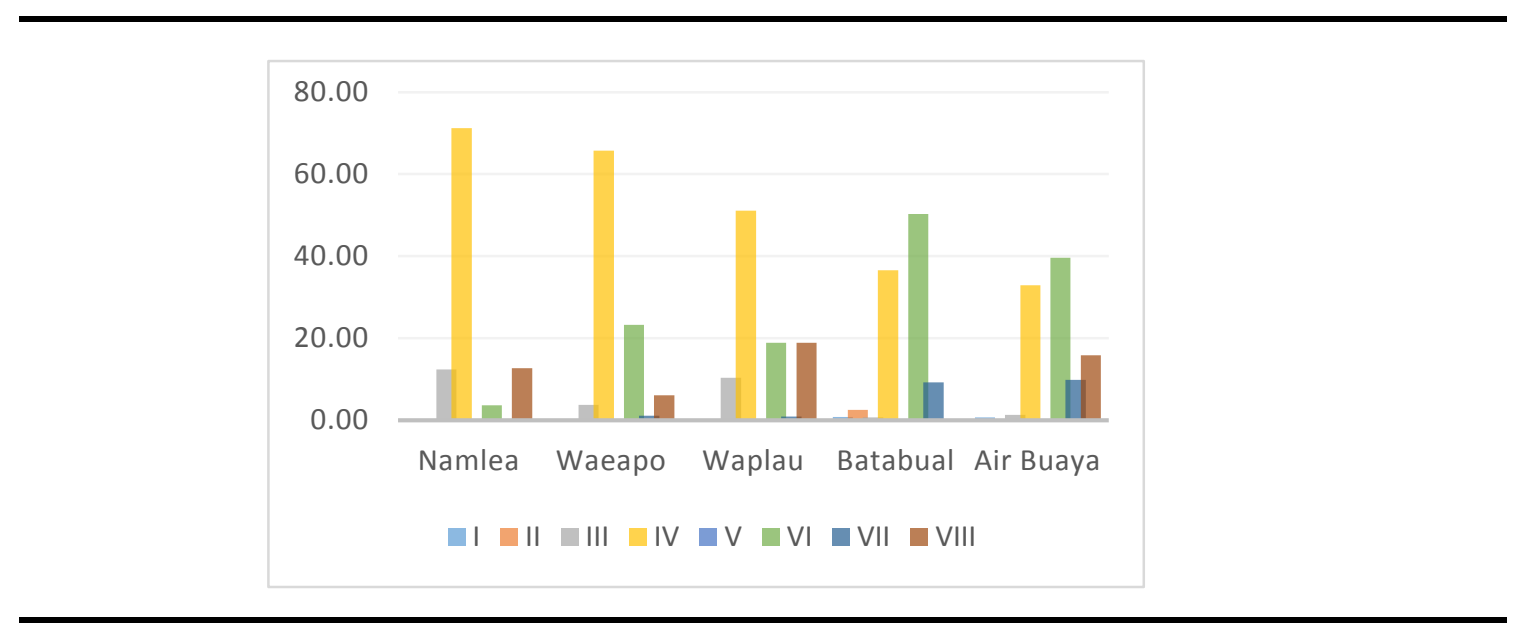

Gambar 8. Presentase Luas Total Kelas Kemampuan Lahan di Setiap Kecamatan Pada Kabupaten Buru

Tabel 4 menunjukkan kelas kemampuan lahan terluas di Kabupaten Buru adalah kelas kemampuan lahan IV dengan luas area 196.099 Ha atau 44,06 persen dari total luas Kabupaten Buru. Kelas kemampuan lahan dengan luasan terbesar kedua adalah kelas VIII yaitu sebesar $169.323 \mathrm{Ha}$ atau 38,05 persen. Kelas kemampuan lahan I merupakan kelas dengan luasan terendah yaitu sebesar $1.584 \mathrm{Ha}$ atau 0,36 persen.

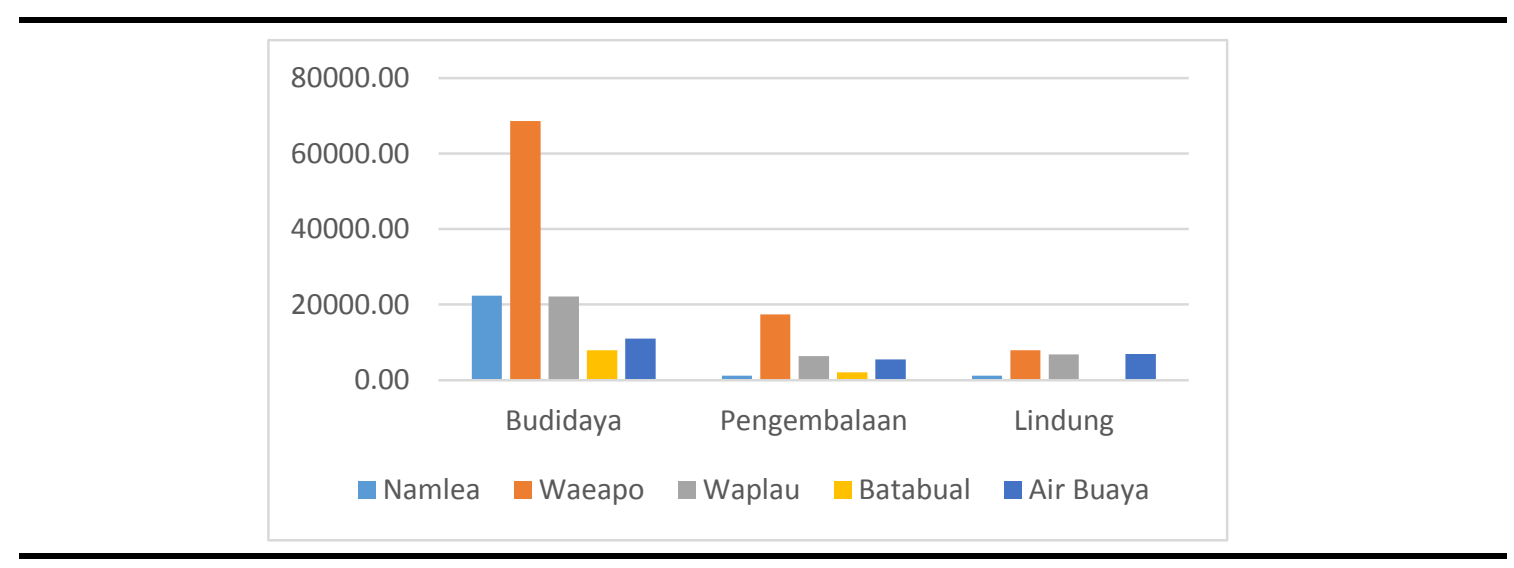

Gambar 9 Total Luas Potensi Lahan Tiap Kecamatan di Kabupaten Buru 
Tabel 4 Luas (Ha) dan Proporsi Luas (\%) Kelas Kemampuan Lahan

\begin{tabular}{lllllll}
\hline \multirow{2}{*}{ No } & Kelas & Kemampuan & Sub Kelas Kemampuan & \multicolumn{2}{c}{ Luas } & \multicolumn{3}{c}{ Luas Total } \\
& Lahan & & Ha & $\%$ & Ha & $\%$ \\
\hline 1 & I & I & 1.584 & 0,36 & 1.584 & 0,36 \\
2 & II & II(ke) & 226 & 0,05 & 1.765 & 0,40 \\
& & II(t,i) & 1.539 & 0,35 & & \\
3 & III & III(c,ke) & 2.919 & 0,66 & 26.544 & 5,96 \\
& & III(c) & 279 & 0,06 & & \\
& & III(i) & 2.027 & 0,46 & & \\
4 & IV & III(ke) & 21.319 & 4,79 & & \\
& & IV(d) & 152.613 & 34,29 & 196.099 & 44,06 \\
& & IV(i) & 35.525 & 7,98 & & \\
5 & V & IV(d,ke) & 7.961 & 1,79 & & \\
6 & VI & - & - & - & - & - \\
7 & VII & VI(i) & 30.216 & 6,79 & 30.216 & 6,79 \\
8 & VIII & VII(i) & 19.527 & 4,39 & 19.527 & 4,39 \\
& & VIII(i) & 148.086 & 33,27 & 169.323 & 38,05 \\
& & VIII(t) & 21.237 & 4,77 & & \\
& & Total & 445.057 & 100 & 445.057 & 100 \\
\hline
\end{tabular}

Sumber : Hasil Olahan, 2015

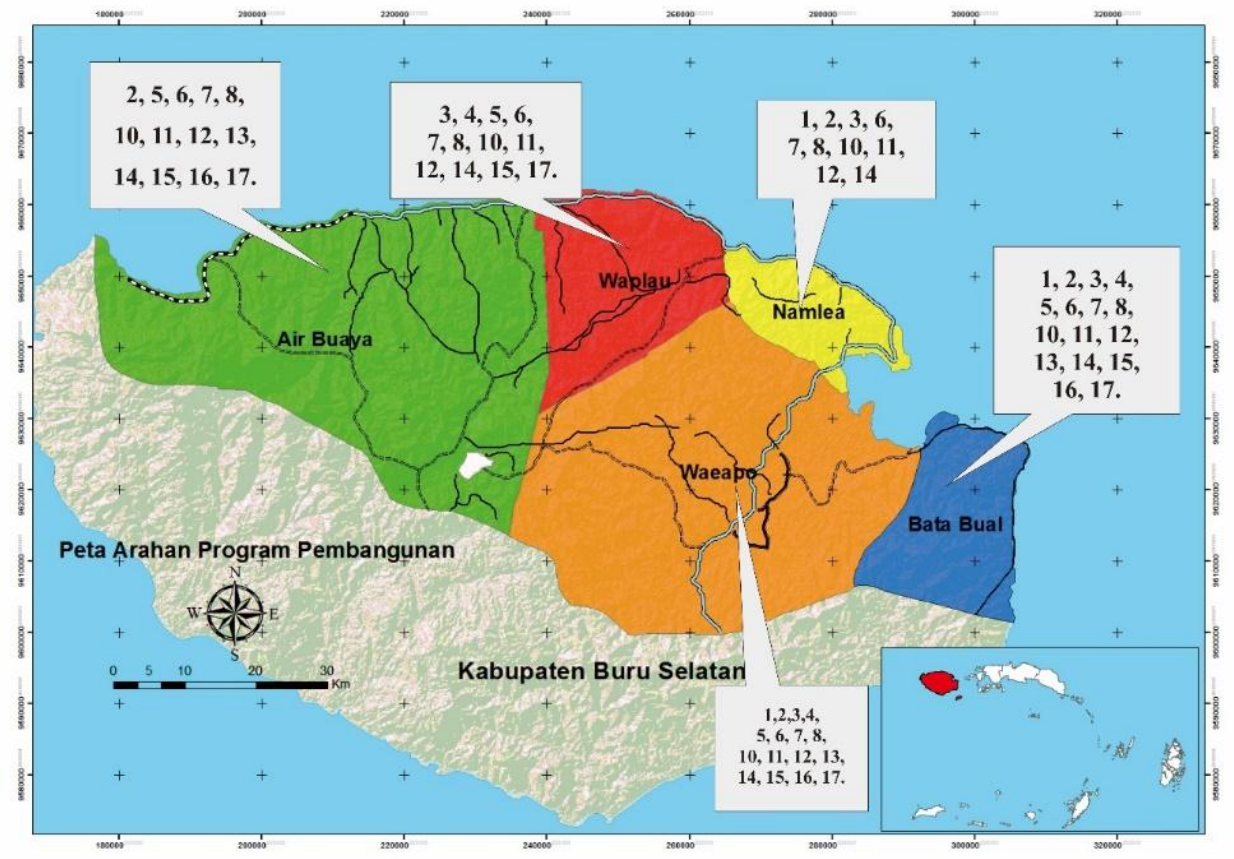

Gambar 10 Peta Arahan Program Pembangunan

\section{Arahan Program Pembangunan}

Arahan program pembangunan disusun dalam matriks berdasarkan fakta sebelumnya yang dirangkum pada Tabel 5. Selanjutnya arahan tersebut di letakkan dalam setiap kecamatan seperti disajikan pada Tabel 6 dan Gambar 10. Secara keseluruhan ditemukan kesamaan dan perbedaan pada setiap kecamatan, arahan yang sama pada setiap kecamatan adalah (10) Pengembangan kawasan sesuai kemampuan lahan yang ada, (11) 
Pengembangan pertanian berdasarkan kemampuan lahan yang tersedia, (12) Pembangunan jaringan jalan, saluran air (selokan) dan jembatan penghubung, selain ketiga arahan ini ada juga yang terdapat di 4 kecamatan yaitu (15) Penyediaan tenaga kesehatan dan pengajar, dan (17) Penyediaan sarana pendukung pertanian seperti tempat penjualan pupuk, bibit dan tempat penjualan hasil produksi.

\section{Tabel 5 Arahan Program Pembangunan}

\begin{tabular}{|c|c|c|c|}
\hline A. & Ketimpangan Pembangunan & B. & Komoditas Unggulan \\
\hline C. & $\begin{array}{l}\text { Pembangunan jaringan jalan untuk } \\
\text { memudahkan akses kegiatan masyarakat } \\
\text { (Kec. Namlea dan Batabual). }\end{array}$ & I. & $\begin{array}{l}\text { Pengembangan pertanian yang berpusat pada } \\
\text { keunggulan komparatif dan kompetitif di tiap } \\
\text { kecamatan. }\end{array}$ \\
\hline D. & $\begin{array}{l}\text { Pembangunan dan distribusi fasilitas } \\
\text { pendidikan. }\end{array}$ & $\mathrm{J}$. & $\begin{array}{l}\text { Pembangunan sarana pendukung pengembangan } \\
\text { pertanian. }\end{array}$ \\
\hline E. & $\begin{array}{l}\text { Pembangunan dan distribusi fasilitas } \\
\text { kesahatan. }\end{array}$ & $\mathrm{K}$. & $\begin{array}{l}\text { Pengembangan sawah di Kabupaten Buru, karena } \\
\text { letaknya sebagai salah satu Kabupaten lumbung padi }\end{array}$ \\
\hline & $\begin{array}{l}\text { Penyebaran tenaga kesehatan (Kec. Air } \\
\text { Buaya, Waeapo, Waplau dan Batabual). }\end{array}$ & & di Provinsi Maluku (Kec. Waeapo) \\
\hline G. & Pengembangan pusat kegiatan lain. & & \\
\hline H. & $\begin{array}{l}\text { Pembangunan akses penunjang fasilitas } \\
\text { pendidikan dan kesehatan. }\end{array}$ & & \\
\hline L. & Kemampuan dan Potensi Lahan & M. & Presepsi Masyarakat \\
\hline $\mathrm{N}$. & $\begin{array}{l}\text { Pengembangan kawasan sesuai kemampuan } \\
\text { lahan yang ada. }\end{array}$ & P. & $\begin{array}{l}\text { Pembangunan jaringan jalan, saluran air (selokan) } \\
\text { dan jembatan penghubung. }\end{array}$ \\
\hline \multirow[t]{5}{*}{ O. } & $\begin{array}{l}\text { Pengembangan pertanian berdasarkan } \\
\text { kemampuan lahan yang tersedia. }\end{array}$ & Q. & $\begin{array}{l}\text { Pembangunan jaringan listrik (Kec. Batabual dan Air } \\
\text { Buaya). }\end{array}$ \\
\hline & & R. & Pembangunan sarana pendidikan dan kesehatan. \\
\hline & & S. & Penyediaan tenaga kesehatan dan pengajar. \\
\hline & & & $\begin{array}{l}\text { Pengembangan pasar-pasar lokal (Kec. Air Buaya } \\
\text { dan Batabual). }\end{array}$ \\
\hline & & U. & $\begin{array}{l}\text { Penyediaan sarana pendukung pertanian seperti } \\
\text { tempat penjualan pupuk, bibit dan tempat penjualan } \\
\text { hasil produksi. }\end{array}$ \\
\hline
\end{tabular}

Tabel 6 Hasil Sintesis Arahan Program Pembangunan

\begin{tabular}{|c|c|c|c|c|c|c|}
\hline Kecamatan & Kekurangan & Kelebihan & Potensi Lahan & $\begin{array}{l}\text { Komoditas } \\
\text { Unggulan }\end{array}$ & & Arahan \\
\hline Namlea & $\begin{array}{l}\text { - } \text { Tingkat rasio } \\
\text { jalan buruk. } \\
\text { - } \text { Tingkat } \\
\text { pelayanan } \\
\text { pendidikan } \\
\text { rendah. } \\
\text { - } \text { Tingkat } \\
\text { pelayanan } \\
\text { kesehatan } \\
\text { rendah. }\end{array}$ & $\begin{array}{l}\text { Merupakan } \\
\text { ibukota } \\
\text { kecamatan. }\end{array}$ & $\begin{array}{l}\text { Potensi lahan } \\
\text { untuk } \\
\text { budidaya } \\
\text { seluas } \\
22.390,73 \text { ha. }\end{array}$ & $\begin{array}{l}\text { Memiliki } \\
\text { komoditas } \\
\text { unggulan } \\
\text { terbanyak } \\
\text { sebanyak } \\
\text { komoditas. }\end{array}$ & 14 & $\begin{array}{l}1,2,3,6,7,8 \\
10,11,12,14 .\end{array}$ \\
\hline Waeapo & $\begin{array}{l}\text { Tingkat } \\
\text { pelayanan } \\
\text { fasilitas } \\
\text { pendidikan } \\
\text { rendah. } \\
\text { - Tingkat } \\
\text { pelayanan } \\
\text { fasilitas } \\
\text { kesehatan } \\
\text { rendah. }\end{array}$ & $\begin{array}{l}\text { Tingkat rasio jalan } \\
\text { baik. }\end{array}$ & $\begin{array}{l}\text { Potensi lahan } \\
\text { untuk } \\
\text { budidaya } \\
\text { terluas yaitu } \\
\text { seluas } \\
68.615,62 \text { ha. }\end{array}$ & $\begin{array}{ll}\text { - } & \text { Memiliki } \\
\text { komoditas } \\
\text { unggulan } \\
\text { sebanyak } \\
\text { komoditas. } \\
\text { - } \text { Merupakan } \\
\text { pusat } \\
\text { pertanian } \\
\text { sawah } \\
\text { Kabupaten } \\
\text { Buru. }\end{array}$ & di & $\begin{array}{l}2,3,4,5,6,7 \\
8,9,10,11,12, \\
14,15,17\end{array}$ \\
\hline
\end{tabular}




\begin{tabular}{|c|c|c|c|c|c|c|}
\hline Kecamatan & Kekurangan & Kelebihan & Potensi Lahan & $\begin{array}{l}\text { Komoditas } \\
\text { Unggulan }\end{array}$ & & Arahan \\
\hline Waplau & $\begin{array}{l}\text { - Tingkat } \\
\text { pelayanan } \\
\text { kesehatan } \\
\text { sedang. }\end{array}$ & $\begin{array}{l}\text { - Tingkat rasio } \\
\text { jalan baik. } \\
\text { - Tingkat } \\
\text { pelayanan } \\
\text { fasilitas } \\
\text { pendidikan } \\
\text { tinggi. }\end{array}$ & $\begin{array}{l}\text { Potensi lahan } \\
\text { untuk } \\
\text { budidaya } \\
\text { seluas } \\
22.173,26 \text { ha }\end{array}$ & $\begin{array}{l}\text { Memiliki } \\
\text { komoditas } \\
\text { unggulan } \\
\text { sebanyak } \\
\text { komoditas. }\end{array}$ & 7 & $\begin{array}{r}3,4,5, \\
6,7,8,10,11, \\
12,14,15,17\end{array}$ \\
\hline Batabual & $\begin{array}{l}\text { - } \text { Tingkat rasio } \\
\text { jalan buruk. } \\
\text { - Tingkat } \\
\text { pelayanan } \\
\text { pendidikan } \\
\text { rendah. } \\
\text { - Tingkat } \\
\text { pelayanan } \\
\text { kesehatan } \\
\text { rendah. }\end{array}$ & & $\begin{array}{l}\text { Potensi lahan } \\
\text { untuk untuk } \\
\text { budidaya } \\
\text { seluas } \\
7.920,27 \text { ha. }\end{array}$ & $\begin{array}{l}\text { Memiliki } \\
\text { komoditas } \\
\text { unggulan } \\
\text { sebanyak } \\
\text { komoditas. }\end{array}$ & 6 & $\begin{array}{l}1,2,3,4,5,6, \\
7,8,10,11,12, \\
13,14,15,16, \\
17 .\end{array}$ \\
\hline Air Buaya & $\begin{array}{l}\text { Tingkat pelayanan } \\
\text { pendidikan rendah }\end{array}$ & $\begin{array}{l}\text { - Tingkat rasio } \\
\text { jalan baik. } \\
\text { - Tingkat } \\
\text { pelayanan } \\
\text { fasilitas } \\
\text { kesehatan } \\
\text { tinggi. } \\
\end{array}$ & $\begin{array}{l}\text { Potensi lahan } \\
\text { untuk untuk } \\
\text { budidaya } \\
\text { seluas } \\
10.985,77 \text { ha. }\end{array}$ & $\begin{array}{l}\text { Memiliki } \\
\text { komoditas } \\
\text { unggulan } \\
\text { sebanyak } \\
\text { komoditas. }\end{array}$ & 6 & $\begin{array}{l}2,5,6,7,8,10 \\
11,12,13,14 \\
15,16,17 .\end{array}$ \\
\hline
\end{tabular}

\section{KESIMPULAN}

Ditemukan ketimpangan di Kabupaten Buru pada beberapa fasilitas pelayanan antara lain jalan, fasilitas pendidikan dan fasilitas kesehatan. Kecamatan yang mempunyai pelayanan fasilitas terendah adalah Kecamatan Namlea, sedangkan 4 kecamatan yang lain menunjukkan hasil yang beragam. Pola ketimpangan yang terjadi di Kabupaten Buru untuk fasilitas jalan terlihat pada Kecamatan yang berada di sebelah kanan yaitu Kecamatan Batabual dan ibukota kabupaten yaitu Kecamatan Namlea, untuk fasiltas kesehatan pola ketimpangan terjadi pada kecamatan di sebelah kanan yaitu Kecamatan Namlea, Waeapo dan Batabual dan untuk ketimpangan fasilitas pendidikan pola ketimpangan terlihat menyebar yaitu pada Kecamatan Namlea, Air Buaya dan Waeapo. Kecamatan Namlea yang menjadi kecamatan dengan tingkat ketimpangan yang tinggi hal ini disebabkan karena pada kecamatan ini memiliki jumlah penduduk terbanyak dengan kepadatan yang tinggi.

Berdasarkan analisis LQ dan SSA di Wilayah Kabupaten Buru, Komoditas yang menjadi unggulan di tiap Kecamatan hampir sama, tetapi ada 3 kecamatan yang memiliki komoditas yang menjadi unggulan dan tidak menjadi unggulan di kecamatan lain yaitu Kecamatan Namlea ( ubi jalar dan pisang), Kecamatan Waplau (bawang merah) dan Kecamatan Batabual (cengkih), akan tetapi pada Kecamatan Waeapo yang menjadi sentra produksi padi juga harus menjadi perhatian pemerintah untuk pengembangannya karena merupakan pemasok beras untuk Kabupaten Buru dan Provinsi Maluku.

Luas potensi lahan yang dapat dimanfaatkan untuk budidaya pertanian untuk tiap kecamatan yaitu Kecamatan Namlea (22390,73 ha), Kecamatan Waeapo (68615,62 ha), Kecamatan Waplau (22173,26 ha), Kecamatan Batabual (7920,27 ha) dan Kecamatan Air Buaya (10985,77 ha).

Arahan program pembangunan yang dihasilkan sesuai dengan fakta yang ditemukan dapat menjadi dasar untuk dipertimbangkan dalam pengembangan kawasan untuk mengatasi disparitas antar kecamatan di Kabupaten Buru. 


\section{DAFTAR PUSTAKA}

[BPS] Badan Pusat Statistik Kabupaten Buru. 2014. Kabupaten Buru Dalam Angka.

[FAO]. Food and Agriculture Organization. 1976. A Framework for land evaluation. Rome (IT); Soil Bulletin 32 .

Hardjowigeno, S. Widiatmaka. 2007. Evaluasi Kesesuaian Lahan dan Perencanaan Tata Guna Lahan. Bogor : Gadjah Mada University Press

Mahalaya S. 1989. Perencanaan Pengembangan Pertanian Berdasarkan Kelas Kemampuan Lahan dan Analisa Sewa Ekonomi Lahan (Land Rent) (Studi Kasus di Desa Tapos Kecamatan Parungpanjang Kabupaten Bogor). [tesis]. Bogor (ID): Sekolah Pascasarjana Bogor.

Mohiuddin S dan Hashia H. 2012. Regional socio-economic disparities in the Kashmir Valley (India) - a geographical approach. Bulletin of Geography. Socio-economic Series No. 18 (2012): 85-98.

Mopangga H. 2011. Analisis Ketimpangan Pembangunan dan Pertumbuhan Ekonomi di Provinsi Gorontalo. Jurnal Trikonomika.10 (1):40-51

Nashiha M, Turmudi, Nahib I. 2015. Arahan Peruntukan Ruang Kawasan Perkebunan Dengan Menggunakan Pendekatan Sistem Lahan Studi Kasus : Kabupaten Lombok Tengah. Majalah Ilmiah Globe. 17(2):181188

Pose AR dan Tselios V. 2010. Inequalities in income and education and regional economic growth in western Europe. Annual Regional Science. 44:349-375

Rustiadi E, Saefulhakim S, Panuju DR. 2011. Perencanaan dan Pengembangan Wilayah. Jakarta (ID): Crestpent Press dan Yayasan Pustaka Obor Indonesia.

Sari MR. 2010. Analisis Komoditi Unggulan Pertanian Di Pulau Buru, Provinsi Maluku. Universitas Pattimura. Agroforestri. 5(3):228-236.

Syahidin A. 2006. Studi Kebijakan Pengembangan Berbasis Sektor Unggulan : Kasus Kabupaten Kebumen Provinsi Jawa Tengah. [tesis]. Bogor (ID): Sekolah Pascasarjana Bogor

Syafruddin, Kairupan AN, Negara A, Limbongan J. 2004. Penataan Sistem Pertanian dan Penetapan Komoditas Unggulan Berdasarkan Zona Agroekologi di Sulawesi Tengah. Jurnal Litbang Pertanian 23(2):61-67. 